\title{
Study for the Wide-area Protection Schemes Coping with Abnormal Trip Phenomenon
}

\author{
B. R. PAN, X. Z. GUI, G. N. WANG, R. X. FAN, J. B. XIN \\ Jiangxi Electric Power Research Institute, Nanchang, China.
}

\begin{abstract}
Several severe power failures occurred in recent years, the reason of which are common faulttrip-cased flow transferring. This phenomenon can lead to abnormal trip of load flow protection, and at worse result in intertripping. To prevent potential power failures, wide area protection based on wide area measurement was proposed. Wide area protection systems can be divided into two parts: wide area backup protection and wide area emergency control. The first part of the paper introduces the development process of cascading outages, principles, characteristics and classification of wide area backup protection. The second part of the paper focuses on structure and control mode of wide area backup protection system and the improvement of various structures to the performance of the traditional back up protection. In the last part, three kind of wide area backup protection which bases on current differential principle, direction comparison principle and multiAgent is introduced. They are the major forms of centralized protection and distributed protection respectively. KEYWORD: wide area protection; wide area backup protection; centralized; distributed
\end{abstract}

\section{BACKGROUND}

With the occurrence of numerous event of great significance in China these years, for instace, the construction of Three-Gorge Hydropower Station, implementation of National power network, west-east power transmission and et al, national power grid is now in a critical juncture and a booming time access to modern ones.

Along with the expansion of interconnect area of power network, the enhancement of exchange capacity and the increase of voltage level, nevertheless, fault-cased power failures gradually become catastrophizing and play an influential role in daily life. Take America, which is highly modernized in economy and science, as an example, one of the cases among power failure incidents is within America-Canada grid on 8,14th,2003 ,which caused up to 50million in severe blackout and resulted in heavy economic loss.

The reason of blackout could be recognize as maloperation by existing protective relaying. Existing design philosophy based on local data may lead to phenomena as follows. On one hand, tripping of transmission lines within main transmission sections can cause flow transferring, and relaying on remaining overload lines have great probability to maloperation because of loss for working conditions of the whole regional power grid in local-data-based protective unit. On the other hand, fault duration usually has great internal relation with stability of $\mathrm{HV}$ power grid. The longer the former one is, the weaker the later one could be. So if backup protection makes use of data remote information, contraction of time delay, rapid tripping and backup protection operation acceleration can be achieved [1].

WAMS (Wide-Area Measurement System) develops accompanied by computer and communication science, and on this basis, principle of WAMS was put forward by a Sweden scholar named Bertil Ingelsson in 1977, aiming at prevention for voltage collapse and stability controlling [2]. WAMS was put together with protective relaying in Japan. Data transmission speed was highly increased and wide area protection came into practical by making use of GPS and fiber channel, with the former one gaining time tick and the later one sending multipoint grid condition message via specified fiber channel [3].

Two kinds of wide are protection system are proposed at present. One is for security monitoring, controlling, stability boundary calculating, dynamic security assessment and et al, with its function emphasis on utilization of wide-area data and realization of safety. The other is for wide-area-databased protective relaying, and they put existing protective relaying forward by promoting point-based strategy to section-based ones [4-5]. 
According to several international power failures, it is confirmed that severity of consequence is in positive correlation with the scale of the grid. Meanwhile, wide-are data is more available with the growth of computer science and communication technology, with information theory evolving, it is quite possible for the construction of time-real integration platform for protection and emergency controlling [6-7]. The study for wide-are protection is a major practical problem of the development of national power system and overall direction of protection and emergency controlling information technology give birth to.

\section{FUNDAMENTAL PRINCIPLE}

It is indicated from the intertripping-caused fault that modern protection scheme is required to face the grid as a whole with its protection area ranging from single device to the entire grid. The function of modern protective relaying is not just to remove faulted component, and to coordinate with automatic control device, load shedding or machine shedding as an example, as well.

\subsection{Process of intertripping}

It can be deduced from the action sequence of the protection device that the process of intertripping event can be described as follows [8].

i. Partial failure happened and cleared when some of the grid elements are in outage and to be renovated.

ii. Partial elements overload after fault clearance and state transferring of the grid.

iii. Overloaded transmission element cut off by backup protection, overload phenomenon happened elsewhere.

iv. System unstable after clearance of chain overload which gives rise to the transferring of transmission line corridors.

v. Low-frequency, low-voltage load shedding and automatic high-frequency machine-shedding devices action dispersedly, leading to system crashing after system becomes unstable.

Figure 1shows a simple three-generator model system, whose numerator and denominator in rectangular frame represent current value and upper limit value of transmission power. When one of the three lines of transmission section between A-F is in outage and to be renovated it is does no harm to other devices. It is clear that only $8 / 15$ and 4/9 of maximal transmission capacity is utilized for bus $\mathrm{F}$ and section A-F, which means a high margin for security.

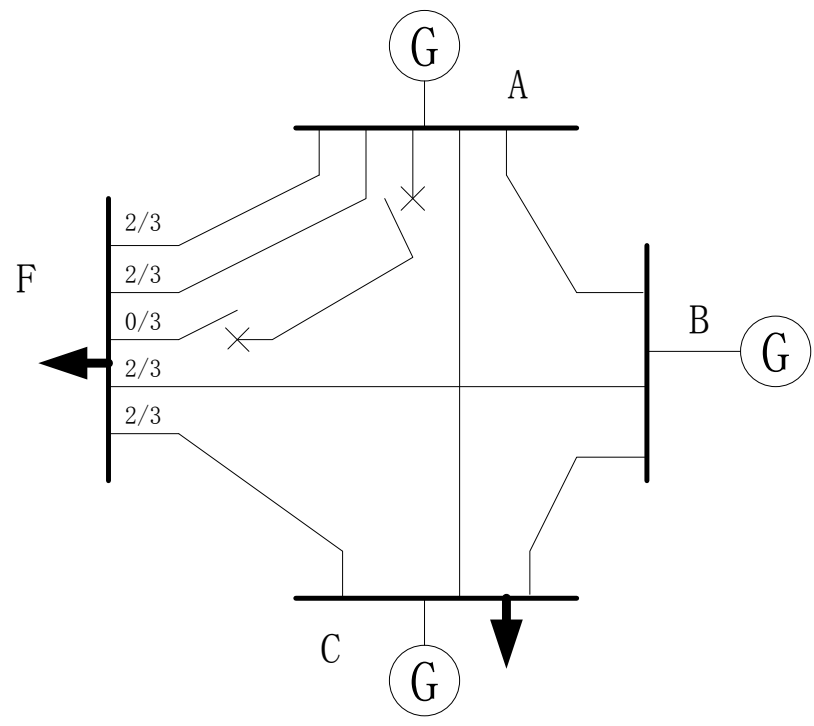

Figure1. Three-generator model system.

Figure 2 shows a case of overload caused by permanent single-phase-to-ground fault in A-F transmission section after ineffectual auto-reclosure, which lead to one single overloading line remaining in A-F section.

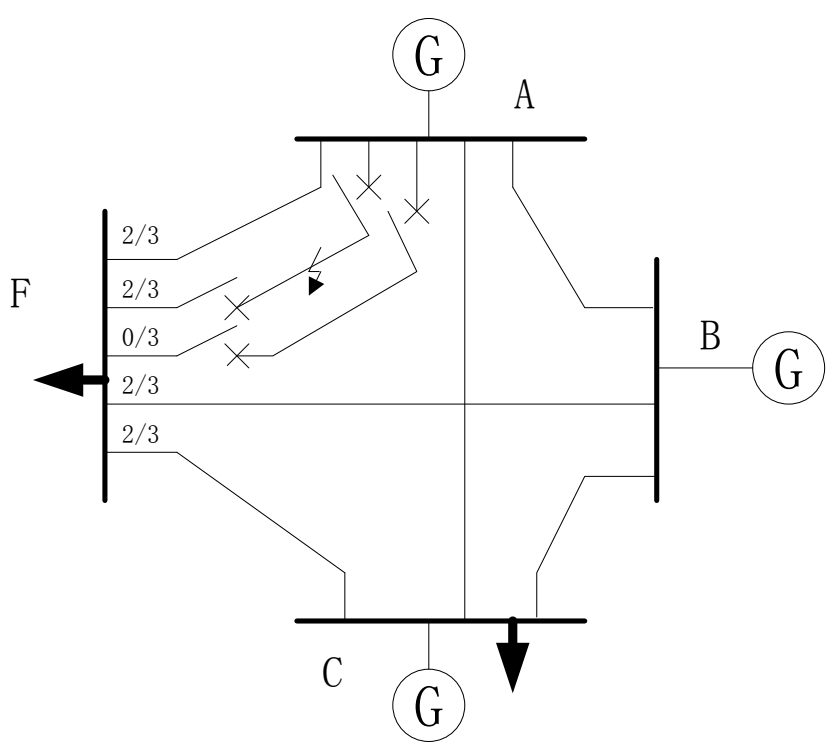

Figure2. Tripping of fault line.

Existing auto device being in no correlation with protective relaying, overload protection act itself to sever all linkage between A-F section., resulted in original flow transferring to $\mathrm{B}-\mathrm{F}$ and $\mathrm{C}-\mathrm{F}$, and corresponding backup protection start up to cut off B-F and C-F. This can lead to complete separation between $\mathrm{F}$ and the grid. 


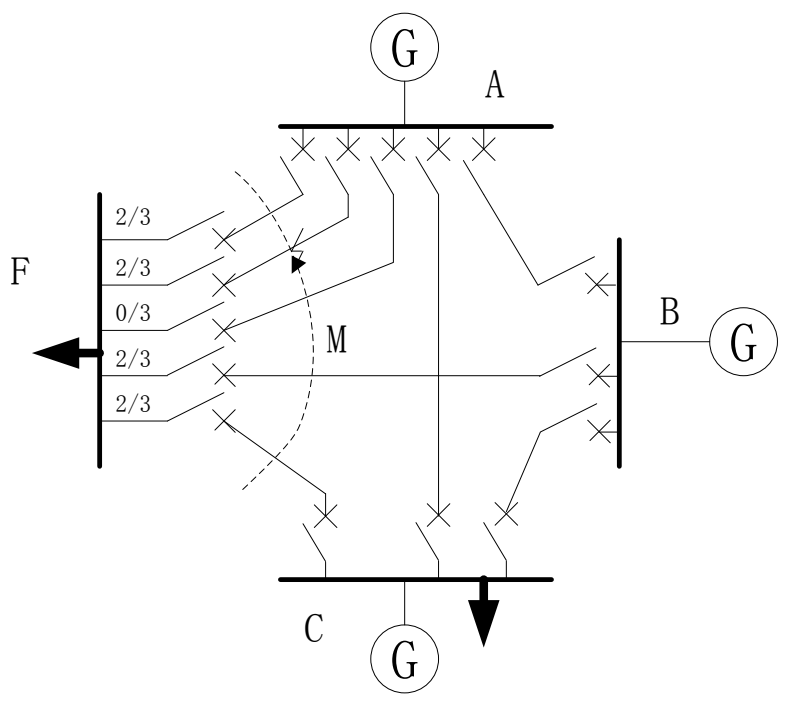

Figure3. Split of an entire network.

After the split of bus F, each machine accelerates due to power surplus, with different acceleration according to their inertia. Suppose that bus A has the maximal power surplus and the generator behind it accelerates most. So the generator behind bus A will be out of step first with bus B and C, which resulted in further split of $\mathrm{M}$ section and separation of bus $\mathrm{A}$. Hardly can the remaining system be stable absolutely, and with further out of step causing chain effect, B-C section well split again as is shown in Figure 3 With the effect of high-frequency machine-shedding device equipped in each power station, part of generators can still work in parallel with local load if machineshedding setting value is in perfect coordinate with movement speed. Otherwise entire generator would be cut off and system are in blackout from which it could hardly recover.

Therefore the principle only based on local electrical data needs to be reconsidered. Unlike typical faults, there is no doubt that the protection means of overload elements are no longer rapid removal, but to consider the grid as a whole, taking several optimization measures aiming at improving integral security of the grid and minimizing power failure area. Nevertheless, protective relaying based on local message cannot achieve the function above. Hence only equipping wide are protection system can we make elements work coordinate with each other using multi-point data, avoiding severe power failure caused by chain tripping.

\subsection{Wide-Area Measurement System(WAMS)}

WAMS is now a hot issue in power system which can seize real time message in identical reference time utilizing GPS synchronous time signal. It provide novel road to the operation and controlling of largescale interconnected power system because of its perfect solving to synchronization issue. As a further extend to traditional SCADA system only for steady- state process, WAMS has the basic functional unit (PMU) distributed in different nodes of the grid, from which monitoring center acquire node operation message by time real communication network. Data acquired by monitoring center can be used for mass areas such as flow calculation, state estimation and et al.

Based on GPS synchronous uniform time service, WAMS can monitor the operation state of wide area grid synchronously. Time labels are affixed to measured operation messages of the grid by PMU, and are convenient for global analyzing and controlling.

\subsection{Principle and characteristics of wide-are protection}

Wide area protection develops with the growth of microcomputer protection and WAMS, and it can be divided into two parts, with one being terminal protective unit and the other reliable high-speed time real communication network, by which terminal protective unit in wide area protection system can exchange various message about protection state of different place. Thus according to movement strategy defined by wide area protection, terminal protective unit can coordinate and optimize the operation logic of mass protective device distributed among grid space from viewing angle of the whole power grid, promoting the existing protection scheme from point to section.

Wide area protection must operation well in the field of safety emergency controlling via mass terminal protective unit. Emergency controlling requires certain fast controlling method accessing to system stability during severe disturbances or critical faults, such as machine-shedding, fast valving, electrical braking, load shedding, splitting and et al, and the time for effective controlling lasts around few hundred milliseconds. Generally, protection will by all means trip after faults, no matter whether permanent the faults are. Other than protective relaying, emergency controlling system will firstly does quantified judgment, according to which shut down itself if system is stable, and otherwise take appropriate controlling scheme as soon as possible.

Either of the wide area protection system or the traditional protection makes it its mission to clear various faults apace and reliably. The latter one does not take too many stability factor into consideration but the former one does.

In consider of the reliability and independence of protective relaying, fault identification by existing main protection is simple and reliable based on local message, which is irreplaceable. If by any chance happens to be any wrong with communication channel, wide area protection can be shut down as a backup protection system, leaving traditional 
protection and security emergency controlling equipment working alone for the power grid.

\subsection{Classification of wide-area protection}

A wide area protection system based on "three lines of defense" should be functional in two independent aspect, one of which is protection and the other one is security automatic controlling. The key function is reflected in backup protection for wide area protection cannot take the place of traditional fast main protection. Therefore wide area protection could be divided into wide area backup protection system and wide area emergency controlling system according to their own characteristics.

By setting operation scheme according to acquired mass-node data it can be no longer necessary to sacrifice fast-response for selectivity. Based on fault location technic, blackout caused by mistake tripping of backup protection can be overcame. Wide area protection is lower required for transmission time delay for its backup protection position.

Not only can emergency controlling system based on wide area message promote reliability to critical loads, minimizing fault caused blackout area, but also of great significance to large-scale interconnected power system guarding against intertripping. A massive data center is needed to maneuver numerous complicated calculation backstage, for emergency controlling system is not strict with instantaneity as traditional protective relaying would be.

\section{STRUCTURE OF WIDE AREA BACKUP PROTECTION}

Wide area protection can insure selectivity with no sacrifice of tripping time via fault analysis based on wide area message, thus problems like miss tripping of main protection, switch unworkable and so on can be overcame. It can be divided according to structure into two type, with one centralized and the other one distributed. Centralized protection makes decisions by center of controlling, which sending action command to terminal unit. Distributed protection has no controlling center logically, with its function realized absolutely by terminal unit.

\subsection{Centralized structure for wide area protection system}

With double controlling structure, a typical case for the centralized wide area protection system can be describedas Figure4.

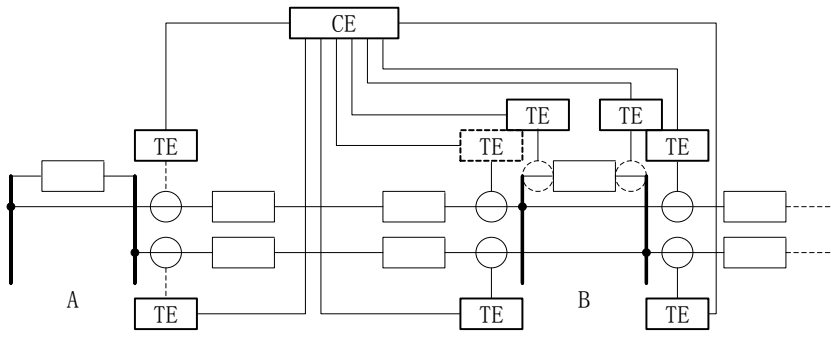

Figure4. centralized wide area protection system.

Substation A\&B are operating in double bus mode with each switch equipped with TE(terminal equipment), and they are under command by a $\mathrm{CE}$ (central equipment). TE firstly process data collected from GPS receiver and then stick them with timestamp, delivering digital data to $\mathrm{CE}$ in the end.

Take protection in substation B as an example. All TEs in it collect local current, voltage, protection output data and position of switch synchronously according to GPS and sent collected data to $\mathrm{CE}$ via fast speed communication network. And it can at the same time receive and execute command message from CE.CE firstly do estimation according to received data during fault and then decide whether fault has been cleared by position of the main protection and switch. If fault is still on after certain seconds, CE starts to send tripping message to related TEs as an acceleration to backup protection.

The characteristic of concentrated controlling method is that $\mathrm{CE}$ collects global data of the grid by which CE estimate fault, sending tripping command to TEs. TEs are of no relationship to each other and have no wide area data, simply executing command from CE passively. With self-checking function, CE is cut off when out of work, leaving traditional protection operating.

\subsection{Distributed structure for wide area protection system}

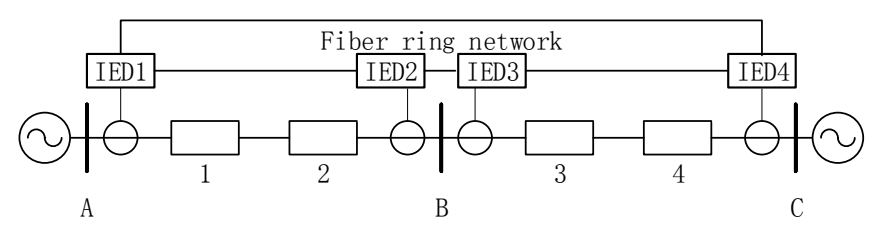

Figure5. Distributed structure for wide area protection system

With distributed structure, each IED is equipped to relevant switch and can collect local data under controlling of GPS, exchanging them with other IEDs via optical fiber ring network, by mean of which each IED can not only collect local data from sensor, but also get wide area data from other IEDs. As a type of backup protection for the grid, IEDs of distributed wide area protection system process fault judgment according to local data synchronously with main protection and send local position message to other 
IEDs, waiting for tripping of main protection. If misstrip happens in main protection, IED send tripping command to relative IEDs in accordance with fault position message and output position of main protection. IED send switch failure message to adjacent switch when fault is still unclear, which operates as backup protection. Compared with traditional backup protection scheme, IEDs of distributed backup protection can send tripping command within range of data sharing to switches when miss-trip or switch failure occurs, realizing backup protection acceleration compared with traditional backup protection.

There being no CE in distributed structure, each terminal unit perceive local state by sensor and acquire global condition via communication with other wide area terminal unit. Thus makes decisions and decides what to execute next according to missions that have to be finished. It is obvious that terminal units of distributed wide area protection system are of great autonomy and interactivity, which reflected in realizing function of wide area protection independent on command messages from $\mathrm{CE}$, and communication among terminal units respectively. It is of significance to the operation of the power grid for that the whole system can still functional even though failure occurs at part of the protection system.

\section{SEVERAL TYPICAL SCHEME FOR WIDE AREA BACKUP PROTECTION}

\subsection{Wide area backup protection based on principle of differential current [9-10]}

The range of wide area protection covers more than single substations. In the light of switch, protection zone is divided into several parts with each part named bus area, transmission line area, main transformer area and et al, with each part cooperates seamlessly.

Wide area backup protection using differential current achieve fault detection based on phase segregated current differential protection. $\mathrm{CE}$ calculates differential current of each section using time-real data from each TE. When differential current is out of limit, CE enters subroutine of fault location, getting state data of output of switch and main protection. If differential current still exists after a short time delay(around $100 \mathrm{~ms}$ ), it can be determined that fault has not been cleared. Meanwhile two different conditions are about to be taken into account, with CE immediately sending tripping command to TE if main protection misstrips, or sending tripping command to adjacent TE when switch failure.

\subsection{Wide area backup protection based on principle of direction comparison [11]}

Utilizing concentrated structure, Wide area protection based on direction comparison firstly form the primary equipment/direction element matrix according to electrical wiring of power station or substation and position of direction element. Wide area protection system starts up after fault occurs, location fault element using changed matrix.

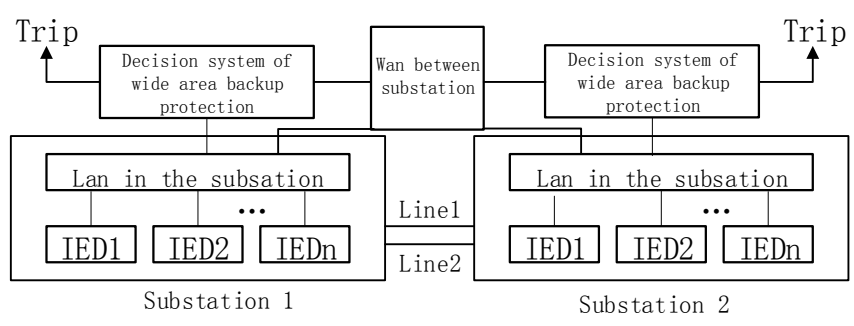

Figure6. wide area protection based on concentrate substation.

1. Make clear protection element.

2. Determine direction element within protection area.

3. Establish original matrix for primary devicedirection element.

4. Initialize matrix.

After locating fault element, wide area protection sending tripping command to relative switch, isolating fault element.

\subsection{Wide area backup protection based on mass Agent technic[12]}

Agent typically means member or node in a group working together, which can be a person, a software, a CUP and et al. In power system, agents are determined to be smart nodes that work in conjunction with those distributed at each corner of the grid. In the field of protective relaying, agent can achieve various performances as intelligentization, correlative working of different protection and et al. MAS-based protection system can be classified as organization level, coordination level and execution level. Fault detection and isolation are accomplished by agents at different levels with its structure graph shown in Figure 7 


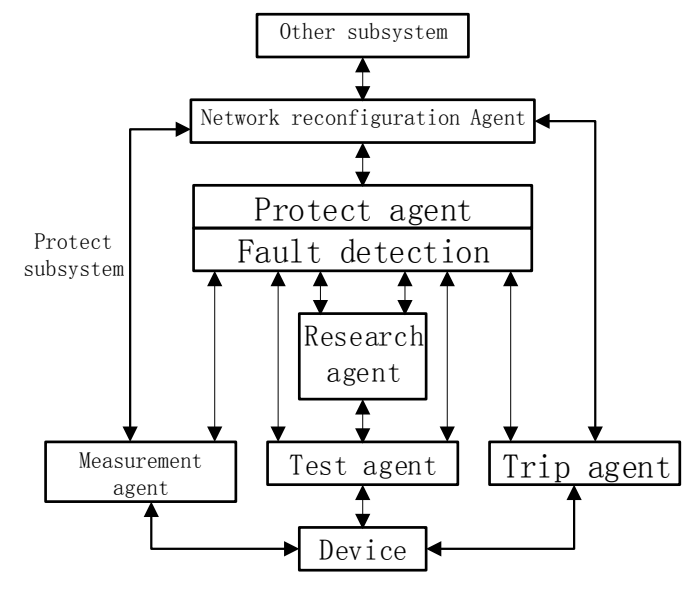

Figure7. wide area protection based on concentrate substation.

According to difference in function, agents are divided into measurement agent, tripping agent, branch searching agent, fault detecting agent, isolation agent, protecting agent and network recombination agent. Protecting agent can be classified into differential agent, distance agent, overcurrent agent, ground agent and et al by various theory.

When fault happened, with local measurement agent detecting fault characteristic quantity, agents in the same equipment with different function handle the fault immediately after inner coordination, and then determine numerous operation ways which must based on selectivity and reliability. After tripping according to inner coordination, if fault characteristic quantities can still be detected, it may be determined to be non-protection factors, and in that case protection at upper level is needed to function as assistance protection. With agent operating at different position, backup protection can trip with no stepped time delay, isolating certain fault immediately.

\section{SUMMARY}

This paper described the Process of intertripping in detail, from which expound the principle of wide area protection. Theory, characteristic and classification of wide area protection was introduced. Wide area backup protection was the main consist of wide area protection, and this paper focuses on structure, controlling method and advantages to existing protection of wide area backup protection in the middle. And at last introduced three kinds of backup protection, which were the main form of concentrated and distributed wide area backup protection.
No matter what kind of structure and controlling method wide area protection used, advantages to existing traditional were similar. Nevertheless as the severe requirement for reliability, traditional main protection will work in coordinate with wide area protection other than being replaced. Wide area protection must has the ability to check itself in real time. Once breakdown, it is cut off immediately, leaving traditional protection working alone.

\section{REFERENCES}

[1] Zhang, B. H. 2004. Problems on protection relay \& urgency control system in interconnected power network of China and studies needed. Electric Power Automation Equipment24 (7): 1-6.

[2] Tan, J. C., Crossley, P. A., McLaren, P. G., Hall, I., Farrell, J., \& Gale, P. 2002. Sequential tripping strategy for a transmission network back-up protection expert system. Power Delivery, IEEE Transactions on, 17 (1), 68-74.

[3] Ota, Y., Ukai, H., Nakamura, K., \& Fujita, H. 2002, October. PMU based midterm stability evaluation of widearea power system. In Transmission and Distribution Conference and Exhibition 2002: Asia Pacific. IEEE/PES (Vol. 3, pp. 1676-1680). IEEE.

[4] Wei, C., Zhencun, P., \& Lei, D. 2004. Wide area protection system to defend three different types of power system stability problems and its application. POWER SYSTEM TECHNOLOGY-BEIJING-, 28 (18), 29-33.

[5] Tan, J. C., Crossley, P. A., McLaren, P. G., Gale, P. F., Hall, I., \& Farrell, J. 2002. Application of a wide area backup protection expert system to prevent cascading outages. Power Delivery, IEEE Transactions on, 17 (2), 375-380.

[6] Cai, J. Y., Lei, W., Morison, K., Kundur, P., Feng-quan, Z., \& Zhi-zhong, G. 2004. Current status and prospect of wide-area protection (dynamic stability control) technologies. POWER SYSTEM TECHNOLOGYBEIJING-, 28 (8), 20-25.

[7] Tomita, Y., Fukui, C., Kudo, H., Koda, J., \& Yabe, K. (1998). A cooperative protection system with an agent model. Power Delivery, IEEE Transactions on, 13 (4), 1060-1066.

[8] Zhang, B. H. 2004. Strengthen the protection relay and urgency control systems to improve the capability of security in the interconnected power network. PROCEEDINGS-CHINESE SOCIETY OF ELECTRICAL ENGINEERING. 24 (7), 1-6.

[9] Lin, X., \& Gao, H. L. 2005. Study of a new type of widearea backup protection scheme. Relay, 33 (7), 84-88.

[10] Lin, X., He, Z., \& LIU, S. 2001. Discussions on some aspects of sampling value differential current protection. AEPS, 10 (10), 27-33.

[11] Yang, Z. L., Shi, D. Y., \& Duan, X. Z. 2008. Wide-area Protection System Based on Direction Comparison Principle. Proceedings of the CSEE, 28 (22), 87-93.

[12] Lu, X., Dai, X., Zhang, T., \& Zhang, K. F. 2002. Multiobjective excitation control based on ANN inverse system method. Automation of Electric Power Systems, 26 (12), 35-39. 